Bangladesh J. Bot. 49(4): 1103-1109, 2020 (December)

\title{
LEAF AREA INDEX RETRIEVAL OF URBAN VEGETATION BASED ON SENTINEL-2 DATA IN ZHONGSHAN, SOUTH CHINA
}

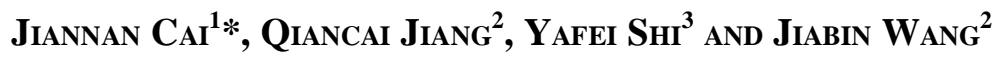 \\ School of Human Settlements and Civil Engineering, Xi'an Jiaotong University, \\ Xi'an, China, 710054
}

Keywords: Leaf area index, Sentinel-2, Remote sensing retrieval

\begin{abstract}
Leaf area index (LAI) is an important indicator of vegetation growth and health monitoring. The free access of Sentinel-2 optical satellite data from European Space Agency (ESA) since June 2015 made it possible to determine dynamic monitoring of LAI in a large area and a short re-entry period, owing to its high spatial resolution (up to $10 \mathrm{~m}$ ) and unique band combination. These features of Sentinel-2 may bring great application potential in urban forestry management and ecological environment monitoring. In case of Zhongshan city in Guangdong Province, based on Sentinels Application Platform (SNAP) software and two scenes of Sentinel-2 data, LAI of the whole city, as well as specific areas, were retrieved and analyzed. The retrieval result was consistent with the ecological spatial pattern and the vegetation protection status in Zhongshan city, also highly consistent with the field LAI measurement in the forest in a reservoir. The result indicates that this method has good applicability and accuracy in urban LAI inversion.
\end{abstract}

\section{Introduction}

Urban vegetation, which can provide a large number of ecosystem services such as temperature reduction and air quality regulation, has been recognized as an important factor for urban ecosystem (Klingberg et al. 2017). Therefore, the process of mapping, quantifying and monitoring changes in the physical characteristics of vegetation has become essential to understand the dynamics of state variables in urban ecosystem (Balacco et al. 2015, Nolè et al. 2015), and the regular and accurate observation of urban vegetation status and damages can facilitate the development of adequate management strategies (Tillack et al. 2014).

The leaf area index (LAI), defined as the one-sided green leaf area per unit ground area, is most widely used as a critical indicator of vegetation productivity, photosynthetic capacity, and degree of stress (Liang et al. 2015, Fang et al. 2018, Kim et al. 2019). LAI can be derived through field sampling method and remote sensing measurements (Chen et al. 2013). Although field method can provide the closest values to the actual LAI, it is quite laborious and time-consuming, which makes it challenging to deploy over large areas and for repeated measurements (Tillack et al. 2014). While the remote sensing approaches offer the advantage of spanning large geographical areas with multiple spatial, spectral and temporal resolutions, which are more cost efficient and enable time-repeated measurements (Sandmann et al. 2013). Therefore, remote sensing technology has been widely used to estimate the spatiotemporal variation in the biophysical and biochemical parameters of vegetation, including LAI (Liang et al. 2015).

The launch of Sentinel-2 satellite provided a new approach of LAI retrieval. The Sentinel-2 satellite carries one multi-spectral instrument (MSI) with a swath width of $290 \mathrm{~km}$. It provides 13 spectral bands, featuring four bands at $10 \mathrm{~m}$, six bands at $20 \mathrm{~m}$ and three bands at $60 \mathrm{~m}$ spatial resolution (Clevers et al. 2017). Among all the bands, four bands are covering the red-edge

\footnotetext{
*Author for correspondence: <jncai@foxmail.com>. ${ }^{1}$ Zhongshan Environmental Monitoring Station, Zhongshan, China, 528403. ${ }^{2}$ Nature Conservation Land Protection and Management Center of Zhongshan, Zhongshan, China, 528403. ${ }^{3}$ Northwest Institute of Eco-Environment and Resources, Chinese Academy of Sciences, Lan Zhou, China, 730099.
} 
spectrum at a spatial resolution of $20 \mathrm{~m}$, which have proven to be essential in LAI mapping (Sibanda et al. 2018). Meanwhile, the ESA provides Sentinel-2 image preprocessing software called Sentinels Application Platform (SNAP), which provides a function called Biophysical Processor, which derives a set of biophysical variables, including LAI from Sentinel-2 reflectances based on specific radiative transfer models. Thus, the advent of Sentinel-2 and SNAP coincides with the growing demand for accurate and affordable spatial datasets and techniques from the forestry and environmental management sector for assessing regional vegetation LAI at regional scales.

In this study, authors used Sentinel-2 images to produce urban LAI retrieval result following the retrieval procedure of SNAP in Zhongshan, a city in South China. Accuracy of the retrieval result, compared with the field measurement from their previous work, was then discussed. The main objective of this study was to assess the potential and utility of Sentinel-2 data for the detection of LAI. This information will be important not only for a better understanding of Sentinel-2 but also for urban LAI monitoring and management.

\section{Materials and Methods}

Zhongshan city lies in the south-central of Pearl River Delta and on the west bank of the Pearl River Estuary, Guangdong Province of South China, located between $113^{\circ} 9^{\prime} 2^{\prime \prime}$ and $113^{\circ} 46^{\prime} \mathrm{E}$ and $22^{\circ} 11^{\prime} 12^{\prime \prime}$ to $22^{\circ} 46^{\prime} 35^{\prime \prime} \mathrm{N}$, with a total land area of $1783 \mathrm{~km}^{2}$. The main landform types of Zhongshan can be divided into four districts, including plain areas in north, southwest, south, and central hilly platform area. The evergreen monsoon rain forest is the typical vegetation in Zhongshan.

As one of the fastest developing regions in recent years, the developed economy and intensive industrial clusters brought high carrying pressure of resources and environment at the same time. With the rapid expansion of construction land, cultivated field and woodland had been seriously occupied, which had brought high impact on the environment of the whole city. Therefore, the study adopting remote sensing technology to analyze the ecological characteristics of vegetation in this region, a typical city in Pearl River Delta, meets the needs of practice management for urban vegetation protection and ecological construction.

Table 1. Description of the four secondary study regions.

\begin{tabular}{lll}
\hline $\begin{array}{l}\text { Region } \\
\text { ID }\end{array}$ & $\begin{array}{l}\text { Region and } \\
\text { description }\end{array}$ & $\begin{array}{l}\text { Total area } \\
\left(\mathrm{km}^{2}\right)\end{array}$ \\
\hline Region 1 & $\begin{array}{l}\text { The land area of Zhongshan National Forest Park. (A national forest park in the } \\
\text { center of Zhongshan, with good preservation of Southern Asian tropical } \\
\text { vegetation) }\end{array}$ & 10.39 \\
Region 2 & $\begin{array}{l}\text { Land reserve of Changjiang reservoir. (The land area at a distance from the } \\
\text { reservoir, mainly composed of water conservation forests) } \\
\text { Region 3 }\end{array}$ & $\begin{array}{l}\text { Public green space in the built-up area. (The main green space types are parks, } \\
\text { urban green belts, and street trees) }\end{array}$ \\
Region 4 & $\begin{array}{l}\text { Flower and tree plantations. (A contiguous zone of plantations, mainly for green } \\
\text { seedlings and flowers cultivation) }\end{array}$ & 5.90 \\
\hline
\end{tabular}

For a detailed study on LAI characteristics of different types of urban vegetation, four secondary study regions representing different structures, amount and type of urban greenery were selected for LAI retrieval result analysis. The secondary study regions are further described in Table 1. 
The cloud-free Sentinel-2 dataset covering the study area were downloaded from the Sentinels Scientific Data Hub (https://scihub.copernicus.eu/) as Level-1C product (with Top-Of-Atmosphere reflectance in cartographic geometry). The sensing date of images used in this study was September 27, 2016, which was closest to the time when the field measurement of LAI in Region 2 was conducted. The SNAP (version 6.0) and Sentinel-2 Toolbox were applied for image preprocessing including atmospheric correction which converting Top-of-Atmosphere (TOA) reflectance into Top-of-Canopy (TOC) reflectance, to facilitate the accurate extraction of wattle reflectance values. Before LAI retrieval, the corresponding bands were re-sampled to a spatial resolution of $10 \mathrm{~m}$ then converted to hdr \& dat format (An image format defined by Esri Inc.). The LAI retrieval can be conducted according to the biophysical processor tool in SNAP. The proposed algorithm in this tool is mainly based on the radiative transfer model. According to this algorithm, a comprehensive database of vegetation characteristics and the associated TOC reflectance can be generated. Neural networks are then trained to estimate the canopy characteristics from the TOC reflectance along with set corresponding angles defining the observational configuration. The LAI outputs will be provided by the application of the algorithm over each pixel. In addition to the production values, quality flags are also generated which describe the validity of the output. The process, such as spatial analysis, data statistics, and image rendering of the LAI outputs were then operated in ArcGIS 10.2 software (Esri Inc.). The entire technology flow of Sentinel-2 data processing and LAI retrieval in this study can be described as follows.

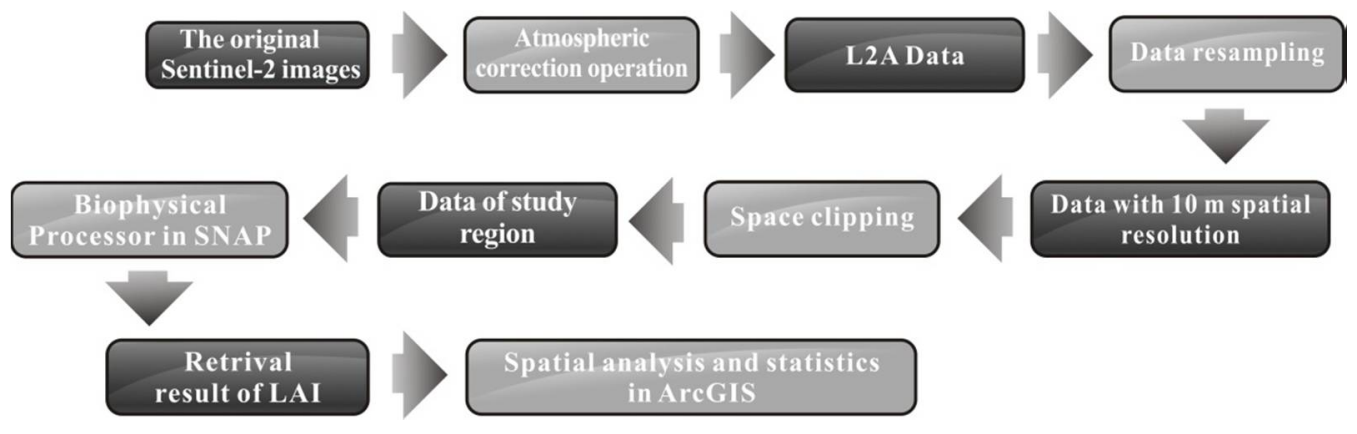

Fig. 1. Technology flow of Sentinel-2 data processing and LAI retrieval.

During September 2015, the authors had carried out field LAI measurement by digital hemispheric photography (DHP) in Land reserve of Changjiang Reservoir. Although this practice was for other research purpose and not for satellite verification specifically, the collected LAI data of sample plots offered an opportunity to assess the usefulness of LAI retrieval by Sentinel-2 data. Fourteen plots were selected from three typical forests, these are, coniferous and broadleaf-conifer mixed forest, evergreen broad-leaved forest, and valley monsoon rainforest. The basic information, including longitude and latitude, elevation, slope, slope direction and slope positions were recorded, respectively. The trees with breast diameter greater than $3 \mathrm{~cm}$ in each plot were investigated. The indexes of breast diameter, height, crown width of trees, and height under branches were also recorded. In each sample plot, the hemispherical images of forest canopy were taken using a Nikon CoolPix4500 and a Nikon FC-8E fisheye converter. The camera was placed at $1.6 \mathrm{~m}$ high from the ground, with the lens facing up. The built-in fisheye mode of the camera was used to take hemispheric images. Gap Light Analyzer 2.0 image processing software was used to analyze the hemispherical photographs to obtain the LAI value. 


\section{Results and Discussion}

According to the algorithm in SNAP, the proposed range of artificial neural network derived LAI over each pixel is 0 to 8 with the resolution of 0.01 . In the case where the artificial neural network provides LAI estimates outside their definition range, the retrieved LAI will be set to the closest bound of the range. However, because of the several sources of uncertainties associated with the inputs and the algorithm calibration, a tolerance with 0.2 is set before raising the 'output out of range' flag. In this study, three cases are possible for each product: (1) The LAI value range from 0 to 8 is considered valid; (2) The value which is within the tolerance limits (0.2) but higher (lower) than $8(0)$ is considered valid but set to the physical maximum (minimum) and (3) The value outside the tolerance limits is considered invalid. According to these three cases and the biophysical processor quality indicator containing information about the validity of the output, the vast majority $(98.11 \%)$ pixels in the study area of retrieved LAI are valid. The pixels with invalid value mainly locate in nearshore waters, and this may be caused by special TOC reflectance in this type of area. The above analysis shows that the retrieval method has satisfactory accuracy. Therefore in the following statistics of this paper, the invalid data are revised and eliminated using the band math tool in ENVI 5.3 (Exelis Visual Information Solutions, Inc.).

To conduct statistics across the city as a whole, the mean value of LAI is 0.82 , with a standard deviation of 0.71 . The LAI value distribution is shown in Fig. 2. The highest frequency of LAI values is about 0.2 to 0.3 , and nearly half of the pixels with valid retrieval result are with low LAI value $(<0.5)$. This low LAI retrieval value reflects that a large proportion of the study area is in the absence of vegetation cover. In the curve of LAI value distribution, a secondary peak appears in the range of 1.8 to 2.0. Combined with the field measurement data below, this range coincides with the field measured value of the forest in land reserve of Changjiang reservoir. Therefore, it can be inferred that this secondary peak reflects the LAI value of typical forest vegetation in the study area.

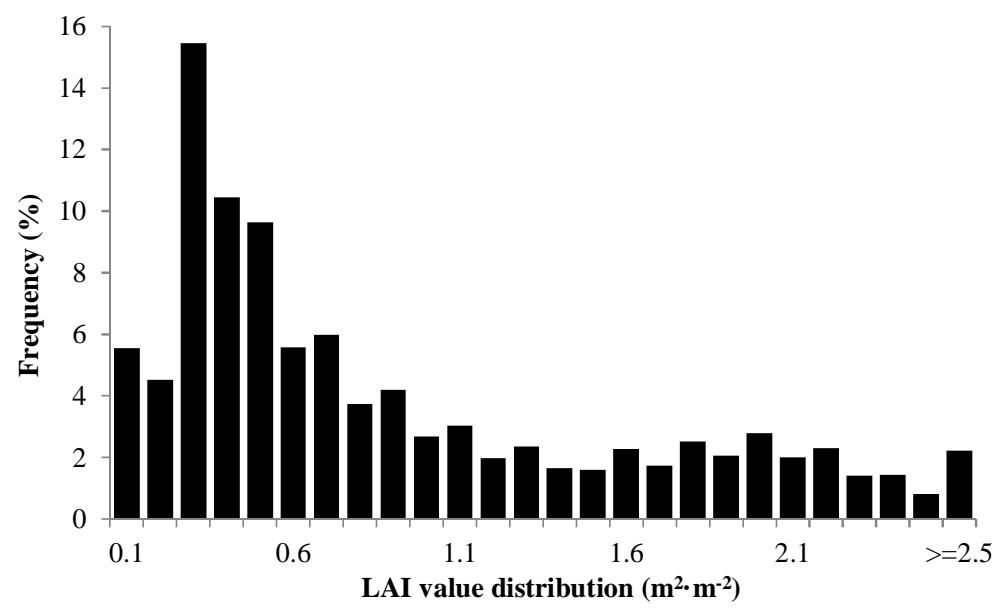

Fig. 2. LAI value distribution interval of Zhongshan.

Based on the map of retrieved LAI spatial distribution (Fig. 3), the regions with high LAI in Zhongshan are located in the south-central part of the city, where assembled most parts of the water conservation area and forest. Such regions have the development directions are mainly to cultivate ecological functions, maintain natural habitats, and provide environmental products, and the retrieval results show that the effects have been achieved in vegetation restore and ecology 
protection. The low LAI value areas are mainly distributed in the urban built-up area in the northwest. This part is the urban sub-center and the gathering area of the equipment manufacturing industry of Zhongshan, with high land use density and construction strength. The process of urban development squeezes a large number of natural green spaces, leading to low vegetation coverage. The patches with high LAI value are scattered in the farmland concentration areas in the northeast of Zhongshan. This area gathered most of the agricultural land and essential farmland protection areas of the city.

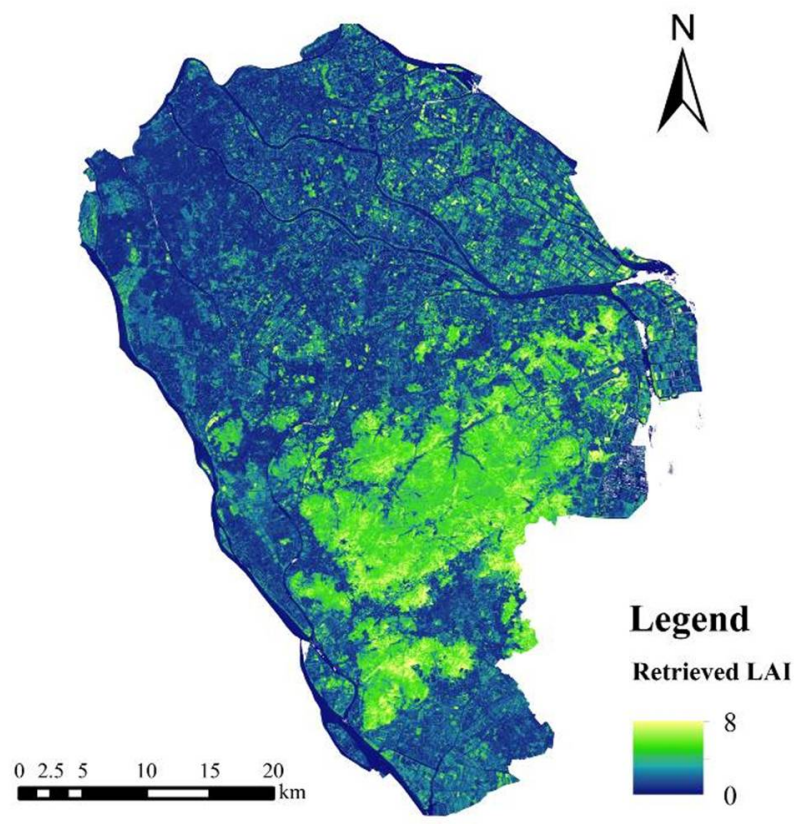

Fig. 3. LAI spatial distribution of Zhongshan.

Using the zone status tool in ArcGIS 10.2, the retrieved LAI of the four secondary study regions were further statistics. The results presented in Table 2, show that the region 3 (Public green space in the built-up area) is with the maximum and standard value, which may be due to the high diversity of vegetation types in this region. Regions 1 and 2, which represent areas with

Table 2. Retrieved LAI of the four secondary study regions.

\begin{tabular}{lccc}
\hline Region ID & \multicolumn{3}{c}{ Retrieved LAI $\left(\mathrm{m}^{2} / \mathrm{m}^{2}\right)$} \\
\cline { 2 - 4 } & Max. & Mean & Std. \\
\hline Region 1 & 3.78 & 1.95 & 0.45 \\
Region 2 & 4.14 & 1.87 & 0.42 \\
Region 3 & 4.47 & 1.15 & 0.67 \\
Region 4 & 2.93 & 0.63 & 0.25 \\
\hline
\end{tabular}

well-preserved subtropical forest vegetation, have similar LAI feature. The LAI of region 4 is the least among all the regions. Overall, the results of LAI retrieval are consistent with the ecological spatial pattern and vegetation protection status of Zhongshan, indicating that this retrieval method by Sentinel-2 data has good applicability and accuracy in the study area. 
The comparison of field measurement and retrieved data are presented in Table 3. The mean value and standard deviation of all sample plots were $1.88 \pm 0.42$ (field measurement data) and $2.10 \pm 0.33$ (retrieved data), respectively. The ratio of field measurement to retrieved data varied from 0.76 to 1.10 , and in general, the retrieved data was generally higher than field measurement.

Table 3. The comparison of field measurement and retrieved data.

\begin{tabular}{|c|c|c|c|c|c|c|}
\hline \multirow{2}{*}{$\begin{array}{l}\text { Plot } \\
\text { ID }\end{array}$} & \multirow{2}{*}{$\begin{array}{l}\text { Forest type and } \\
\text { tree species }\end{array}$} & \multirow{2}{*}{$\begin{array}{l}\text { Stand density } \\
\left(\text { plant } / \mathrm{hm}^{1}\right)\end{array}$} & \multirow[t]{2}{*}{ Latitude } & \multirow[t]{2}{*}{ Longitude } & \multicolumn{2}{|c|}{ LAI value $\left(\mathrm{m}^{2} / \mathrm{m}^{2}\right)$} \\
\hline & & & & & $\begin{array}{c}\text { Field } \\
\text { measurement }\end{array}$ & Retrieved \\
\hline $\mathrm{P} 01$ & $\begin{array}{l}\text { Coniferous forest } \\
\text { (Cunninghamia lanceolate }+ \text { Pinus } \\
\text { elliottii })\end{array}$ & 1922 & 22.41181 & 113.48137 & 2.37 & 2.07 \\
\hline $\mathrm{P} 02$ & $\begin{array}{l}\text { Broad-leaved mixed } \\
\text { (Acacia confuse }+ \text { Manglietia fordiana })\end{array}$ & 2156 & 22.41916 & 113.46384 & 1.49 & 2.16 \\
\hline P03 & $\begin{array}{l}\text { Schima superba forest } \\
(\text { Schima superb }+ \text { Schefflera } \\
\text { octophylla })\end{array}$ & 1467 & 22.42435 & 113.46401 & 1.82 & 2.11 \\
\hline P04 & $\begin{array}{l}\text { Valley monsoon rainforest } \\
\text { (Itea chinensis }+ \text { Machilus breviflora) }\end{array}$ & 3256 & 22.42706 & 113.44639 & 2.00 & 1.80 \\
\hline P05 & $\begin{array}{l}\text { Mixed Broadleaf-conifer forest } \\
\text { (Cunninghamia lanceolate }+ \\
\text { Cinnamomum camphora) }\end{array}$ & 2022 & 22.44619 & 113.46459 & 2.38 & 2.37 \\
\hline P06 & $\begin{array}{l}\text { Schima superba pure forests } \\
(\text { Schima superba }+ \text { Litsea rotundifolia })\end{array}$ & 1144 & 22.44647 & 113.4645 & 2.16 & 2.28 \\
\hline P07 & $\begin{array}{l}\text { Mixed broadleaf-conifer forest } \\
(\text { Schima superba + Pinus massoniana })\end{array}$ & 844 & 22.45597 & 113.43291 & 1.12 & 1.37 \\
\hline P08 & $\begin{array}{l}\text { Broad-leaved mixed forest } \\
\text { (Mytilaria laosensis + Castanopsis } \\
\text { fissa) }\end{array}$ & 2222 & 22.46671 & 113.43368 & 2.17 & 2.28 \\
\hline P09 & $\begin{array}{l}\text { Acacia forest } \\
(\text { Acacia confusa }+ \text { Schima superb })\end{array}$ & 1156 & 22.46951 & 113.45723 & 1.68 & 1.97 \\
\hline $\mathrm{P} 10$ & $\begin{array}{l}\text { Pinus massoniana forest } \\
\text { (Litsea rotundifolia }+ \text { Sapium discolor })\end{array}$ & 944 & 22.47241 & 113.46816 & 1.09 & 1.66 \\
\hline P11 & $\begin{array}{l}\text { Broad-leaved mixed forest } \\
(\text { Schima superba }+ \text { Acacia confuse })\end{array}$ & 2956 & 22.47826 & 113.42212 & 1.98 & 2.24 \\
\hline $\mathrm{P} 12$ & $\begin{array}{l}\text { Broad-leaved mixed forest } \\
\text { (Castanopsis fissa }+ \text { Acacia confuse) }\end{array}$ & 1367 & 22.48319 & 113.44203 & 1.85 & 2.62 \\
\hline $\mathrm{P} 13$ & $\begin{array}{l}\text { Broad-leaved mixed forest } \\
(\text { Schima superba }+ \text { Acacia confuse })\end{array}$ & 1067 & 22.48990 & 113.43430 & 2.34 & 2.51 \\
\hline P14 & $\begin{array}{l}\text { Acacia forest } \\
(\text { Acacia confusa }+ \text { Pinus massoniana })\end{array}$ & 767 & 22.49041 & 113.43642 & 1.88 & 1.95 \\
\hline
\end{tabular}

The results of the two methods were found to right consistency at each sample plot. A positive relationship was found between the field measurement and retrieved data, with Pearson correlation 0.700 and p-value for regression $<0.01$. The above analysis shows that the retrieved LAI by 
Sentinel-2 data and SNAP had good accuracy compared to DHP field measurements. It shows Sentinel-2 data, and this method has good applicability and accuracy in the retrieval of urban vegetation LAI. However, it should also be pointed out that due to insufficient field measurement, it was not possible to compare the retrieved LAI in various types of region in the city. To conduct a comprehensive evaluation of the retrieval accuracy, further exploration in more different types of region should be follow-up.

\section{Acknowledgements}

Work was financed by Ministry of Science and Technology, People's Republic of China, in frames of The National Key Research and Development Program (2017YFC0405900).

\section{References}

Balacco G, Figorito B, Tarantino E, Gioia A, and Iacobellis V 2015. Space-time LAI variability in Northern Puglia (Italy) from SPOT VGT data. Environ. Monit. Assess. 187: 434.

Chen H, Niu Z, Huang W and Feng J 2013. Predicting leaf area index in wheat using an improved empirical model. J. Appl. Remote Sens. 7: 1-25, 25.

Clevers J, Kooistra L and Marnix VDB 2017. Using sentinel-2 data for retrieving LAI and leaf and canopy chlorophyll content of a potato crop. Remote Sens. 9: 405.

Fang H, Ye Y, Liu W, Wei S and Ma L 2018. Continuous estimation of canopy leaf area index (LAI) and clumping index over broadleaf crop fields: An investigation of the PASTIS-57 instrument and smartphone applications. Agric. For. Meteorol. 253-254: 48-61.

Kim J, Ryu Y, Jiang C and Hwang Y 2019. Continuous observation of vegetation canopy dynamics using an integrated low-cost, near-surface remote sensing system. Agric. For. Meteorol. 264: 164-177.

Klingberg J, Konarska J, Lindberg F, Johansson L and Thorsson S 2017. Mapping leaf area of urban greenery using aerial LiDAR and ground-based measurements in Gothenburg, Sweden. Urban For. Urban Green. 26: 31-40.

Liang L, Di L, Zhang L, Deng M, Qin Z, Zhao S and Hui L 2015. Estimation of crop LAI using hyperspectral vegetation indices and a hybrid inversion method. Remote Sens. Environ. 165: 123-134.

Nolè G, Murgante B, Calamita G, Lanorte A and Lasaponara R 2015. Evaluation of urban sprawl from space using open source technologies. Ecol. Inform. 26: 151-161.

Sandmann M, Graefe J and Feller C 2013. Optical methods for the non-destructive estimation of leaf area index in kohlrabi and lettuce. Sci. Hortic. 156: 113-120.

Sibanda M, Mutanga O, Dube T, Vundla TS and Mafongoya PL 2018. Estimating LAI and mapping canopy storage capacity for hydrological applications in wattle infested ecosystems using Sentinel-2 MSI derived red edge bands. GISci. Remote Sens. 1-19.

Tillack A, Clasen A, Kleinschmit B and Förster M 2014. Estimation of the seasonal leaf area index in an alluvial forest using high-resolution satellite-based vegetation indices. Remote Sens. Environ. 141: 52-63.

(Manuscript received on 6 July, 2019; revised on 18 April, 2020) 